ing fossil Isopod from the Irish Devonian. Several other palæontological papers dealt with the problem of extinction, and with certain Annelids, Reptiles, and Insects.

Regarding the congress as a whole, one is struck by its increasing scope. It is attended not only by professional and amateur zoologists, but by anatomists, physiologists, and geologists. The problems it discusses touch upon questions of the greatest. interest to pathologists and to sociologists. The experimental treatment of zoology is being increasingly adopted, whilst the older systematic problems are being studied afresh. The present is a time of data-collecting on an enormous scale, but no fresh principles are as yet forthcoming, and there is a marked tendency to confine the treatment of the subject to noncontroversial matters. One comes away from Graz impressed by the huge amount of zoological work now being done, by the community of spirit that animates its devotees in all countries, and by the value to the cause of peace which such gatherings represent. These sentiments were emphasised in the speeches at the banquet which ciosed the congress.

\section{THE THIRD INTERNATIONAL CONGRESS OF} SCHOOL HYGIENE AT PARIS, AUGUST ${ }_{2-7}$, I910.

THE comparative abstention of German school-hygienists from the third congress was a regrettable feature, and considerably diminished its value from a scientific point of view. The preponderance of Latin influence led to much rhetoric in the sections, and the records of the congress are those of trends of opinion rather than of work accomplished.

The subjects set down for general discussion on the three working days of the congress were, in order:(I) Uniformity of method in medical inspection; (2) instruction in sexual hygiene; and (3) the training and appointment of the school doctor. The first of these alone presented any general scientific interest. A problem awaiting solution is how to frame the records of inspection so that trustworthy statistics can be obtained by which the influence of varying environments can be compared and alterations from decade to decade satisfactorily established. The discussion was opened by Dr. James Kerr in a paper the value of which could not be overestimated. $\mathrm{He}$ postulated that the two aims of medical inspection (the remedial and the statistical) must be separately considered, for no medical inspection carried out on all children is ever likely to be done at public cost to such an extent that it can be of any great value for scientific purposes; when quantitative estimates or comparisons are made, even between schools in the same town or classes in the same school, the results are often not really worth the paper they are written upon. As the result of long experience, he stated that ultimately one is content with only spending as much time as is absolutely necessary on detailed examination, valuable for scientific purposes, and in only examining in such detail sufficient numbers of children to reduce any errors of experiment within such limits that the results will afford a trustworthy standard; the examination of all children in that way is quite unnecessary. For scientific work, he claimed it is best that each topic be examined as a separate problem on data carefully selected and carefully defined by each investigator, and that general inspection should be carried on merely with a definite practical sim of relief to children who present obvious or gross defects. Without this there is great danger of scientific progress being arrested, and the whole movement becoming a lifeless routine of collecting inaccurate and valueless records. It is to be hoped that Dr. Kerr's opinions as here expressed will receive due attention from the authorities in Whitehall, for it is indubitable that much of the work being done in the country at present is utterly unscientific, and has already become the lifeless routine that Dr. Kerr is desirous of guarding against.

The rest of the work of the congress was split up into thirteen sections and sub-sections. Comparing the discussions with those of the second International Congress of 1907 in London, two branches of general school hygiene stand out in which most activity has taken place during the intervening three years. These are physical education and open-air schools. In Section vi., which dealt chiefly with the latter, carefully collated facts were forthcoming which proved alike the wide extension of the movement and the uniform good results obtained without distinction of climate or race. It was Dr. Neufert, of Charlottenburg, who shadowed forth the future developments arising out of the experience gained in the open-air schools. Why should the advantages of the open-air school be limited to the debilitated and unhealthy? If good for them, it must be good also for the normal. All our schools must in future approximate to the open-air ideal, and more activity must take the place of the sedentariness which is now the rule. In connection with the question of activity, it is interesting to note also how the attention paid to manual training has grown during the past three years. Scarcely mentioned in 1907 , its advantages are in 1910 independently pressed in many sections and from many points of view by various workers.

Dr. Mumford, of Manchester, dwelt upon its importance in developing the association centres in the brain where the various sense organs are organised in relation to the combination and arrangement of the muscles. Herr Schrag, of Berne, pointed out the importance of manual training as a link between the various subjects in the curriculum. Prof. Blazek, of Austrian Poland, brought forward the results of ergographical investigations, demonstrating the effects of manual training in developing certain mental qualities of readiness and concentration, and Dr. Schuyten, of Antwerp, supported this with facts proving the effects in diminishing inattention of satisfying the motor needs of the organism.

In Section iv., on physical training, many communications of importance were read. Dr. Digby Bell, of the British Naval School of Physical Exercises, insisted upon the necessity of rescuing the subject from the taint of quackery which still hangs around it. M. Demeny, of Paris, introduced his new system of physical education founded upon continuous movement in opposition to the alternations of fixed contraction and relaxation of muscles upon which older methods are based; his paper was rendered more valuable by a demonstration upon a pupil, which certainly upon æsthetic, and in the writer's opinion upon physiological grounds, showed his method to be superior even to the Swedish movements, which at present hold pride of place in our systems.

A question of great importance to medical inspectors is the discovery of a trustworthy mathematical formula which shall determine the state of nutrition of a child in relation to physical measurements. Prof. Guttmann, of Vienna, examined various formulæ, and came to the conclusion that the best is that of Bornhardt, viz. $G=B L / 240$, where $\mathrm{G}=$ body weight, $\mathrm{B}=$ chest circumference, $\mathrm{L}=$ height, and 240 is a constant representing the mean of a very large number of measurements.

Amongst some valuable papers in Section ix. (teaching methods and syllabuses) was one by Dr. Janale, of Prague, giving the results of extensive investigations on fatigue in the school children of that city by Ebbinghaus's combination method, from which he concluded that a single long morning session per diem is superior to two shorter sessions occupying both morning and afternoon. Another was by Prof. Schuyten on "inattention" as measured in school over yearly periods by dynamometrical experiments accompanied by memory tests. In the first place, inattention is a natural and inevitable result of physiological activity. It is increased by defective conditions of sanitation and diminished by wise distribution of subjects in the time-table. The best results appear to be obtained by not mixing up together daily the various subjects in the curriculum, but by grouping together homologous subjects on each particular day. This is in direct opposition, of course, to the usual arrangement in school time-tables at present.

The congress, it will be seen, presented many features of great general interest, and its practical results will undoubtedly be considerable. It was satisfactory to hear from the lips of one of the Secretaries of State of France, at the concluding meeting, a pledge that the Government would carry into effective operation the proposals upon school hygiene already before the Chamber. 